\title{
Control over Stress, But Not Stress Per Se Increases Prefrontal Cortical Pyramidal Neuron Excitability
}

\author{
Juan A. Varela, ${ }^{1 \star}$ Jungang Wang, ${ }^{1,2 \star}$ John P. Christianson, ${ }^{2}$ Steven F. Maier, ${ }^{2}$ and Donald C. Cooper ${ }^{1,2}$ \\ ${ }^{1}$ Institute for Behavioral Genetics and ${ }^{2}$ Department of Psychology and Neuroscience, University of Colorado at Boulder, Boulder, Colorado 80309
}

Behavioral control over a stressful event reduces the negative consequences of not only that event, but also future stressful events. Plasticity in the prelimbic (PL) medial prefrontal cortex is critical to this process, but the nature of the changes induced is unknown. We used patch-clamp recording to measure the intrinsic excitability of PL pyramidal neurons in acute slices from rats exposed to either escapable stress (ES), for which rats had behavioral control over tail-shock termination, or inescapable stress (IS) without control. Shortly after exposure $(2 \mathrm{~h}$ ) to tail-shock stress, neurons in the ES group had larger action potential (AP) amplitude and faster AP rise rate, larger postspike afterdepolarization, and reduced membrane time constant. No significant effects of IS were observed. We developed a conductance-based computer model using the simulation tool NEURON. The computer model simulated the observed changes in the ES group with increases in $\mathrm{Na}^{+}$conductance $(g \mathrm{Na})$ and T-type $\mathrm{Ca}^{2+}$ conductance $\left(g \mathrm{Ca}_{\mathrm{T}}\right)$. The empirical and computational results indicate that behavioral control over stress, but not stress itself, increases PL pyramidal neuron excitability by increasing intrinsic membrane excitability. It is proposed that plasticity of excitability is important to the behavioral effects of controllable stressor exposure.

\section{Introduction}

Exposure to traumatic stressors contributes to the development of numerous psychiatric conditions. However, not all stressors result in pathology (Southwick et al., 2005). Individual differences in stress response are the product of both innate and psychosocial factors. An individual's perception of control over stress is a potent coping mechanism that may convey resilience to trauma (Yehuda et al., 2006). In rats, behavioral control that allows escape from electric tail-shock prevents the consequences produced by an equal amount of uncontrollable, inescapable shock including: learning deficits, potentiated fear conditioning, potentiated drug reward, and potentiated anxiety (Maier and Watkins, 2005).

Behavioral control over a stressor has the benefit of blunting the impact of the stressor itself, but also reducing the behavioral and neurochemical consequences of future uncontrollable stressors (Williams and Maier, 1977; Amat et al., 2006; Baratta et al., 2009). This phenomenon has been termed "behavioral immunization" and relies on activation of the medial prefrontal cortex (mPFC; Maier and Watkins, 2010). There is evidence supporting a necessary role for increased $\mathrm{mPFC}$ activity as a lasting consequence of control. First, inhibition of mPFC activity during the immunizing controllable stressor or during the subsequent stres-

Received June 4, 2012; revised July 3, 2012; accepted July 8, 2012.

Author contributions: J.A.V., J.P.C., S.F.M., and D.C.C. designed research; J.A.V. and J.W. performed research; J.A.V. and J.W. analyzed data; J.A.V., J.P.C., S.F.M., and D.C.C. wrote the paper.

This study was supported by NIDA Grant DA024040 (D.C.C.), and NIH Grants MH093412 (J.P.C.) and MH050479 (S.F.M.).

*J.A.V. and J.W. contributed equally to this work.

The authors declare no competing financial interests.

Correspondence should be addressed to Donald C. Cooper, Institute for Behavioral Genetics, 1480 30th Street, Boulder, C0 80309. E-mail: dcooper@colorado.edu.

DOI:10.1523/JNEUROSCI.2669-12.2012

Copyright $\odot 2012$ the authors $\quad 0270-6474 / 12 / 3212848-06 \$ 15.00 / 0$ sor prevents acquisition and expression of behavioral immunization, respectively. Accordingly, inhibition of protein synthesis in the mPFC immediately following the experience of control prevents immunization (Amat et al., 2006). The preceding studies did not distinguish between infralimbic (IL) and prelimbic (PL) $\mathrm{mPFC}$, but each makes distinct contributions to emotion expression (Sotres-Bayon and Quirk, 2010). Recent evidence suggests that the PL is critical to behavioral immunization. First, an initial experience with control alters the PL in a way that generalizes to future uncontrollable stressors, which are then capable of activating PL output neurons (Baratta et al., 2009). Furthermore, intra-PL infusions of an NMDA receptor antagonist prevented behavioral immunization (Christianson et al., 2011).

Because the aforementioned studies suggest that controllable stressors increase the excitability of PL projection neurons, we measured the intrinsic electrophysiological properties of layer $5 / 6$ pyramidal neurons in PL after either escapable or inescapable tail-shock. We hypothesized that escapable stress would render these neurons more excitable, relative to uncontrollable stress or naive controls. We then developed conductance-based computer models based on the physiology data to better understand the dynamic physiological mechanisms underlying changes in PL excitability.

\section{Materials and Methods}

Rats. Adult (60-70 d old and weighing 275-350 g) and juvenile (28-32 d old and weighing 90-100 g) male Sprague Dawley rats were bred at the University of Colorado, Boulder. Rats were housed with ad libitum access to food and water in groups of 2 or 3 with a $12 \mathrm{~h}$ light/dark cycle. Stress exposure occurred in the first $4 \mathrm{~h}$ of the light phase. Behavioral procedures were approved by the University of Colorado Institutional Animal Care and Use Committee.

Stress induction procedures. Rats received escapable stress (ES) or inescapable stress (IS), or remained in the home cage (HC). One hundred 
Table 1. Summary of passive properties

\begin{tabular}{llllll}
\hline Treatment & Resting potential $(\mathrm{mV})$ & Input resistance $(\mathrm{M} \Omega)$ & Rectification ratio & Sag ratio & $1.009 \pm 0.001$ \\
\hline HC & $-63.0 \pm 0.8$ & $132 \pm 9$ & $0.81 \pm 0.04$ & $1.007 \pm 0.001$ & $19.2 \pm 0.7^{* *}$ \\
ES & $-62.1 \pm 0.8$ & $106 \pm 12$ & $0.84 \pm 0.04$ & $14.5 \pm 1.1$ \\
IS & $-62.3 \pm 0.7$ & $114 \pm 11$ & $0.81 \pm 0.03$ & $1.010 \pm 0.001$ \\
\hline
\end{tabular}

All values are average \pm SEM.

${ }^{*} p<0.05$ compared with ES, ${ }^{* *} p<0.01$ compared with ES (Tukey's HSD).

$\mathrm{HC}(n=10$ rats, 18 neurons), ES ( $n=8$ rats, 15 neurons) and $\mathrm{IS}$ ( $n=7$ rats, 14 neurons).

Table 2. Summary of single action potential properties

\begin{tabular}{|c|c|c|c|c|c|c|}
\hline Treatment & Threshold (mV) & Rheobase (pA) & AP amplitude (mV) & AP width (ms) & AP rise rate $(\mathrm{mV} / \mathrm{ms})$ & $A D P$ area $(\mathrm{mV} \times \mathrm{ms})$ \\
\hline$H C$ & $-50.2 \pm 0.9$ & $766 \pm 63$ & $95.3 \pm 1.5^{*}$ & $0.88 \pm 0.02$ & $300 \pm 14$ & $116 \pm 21^{*}$ \\
\hline ES & $-50.8 \pm 1.2$ & $887 \pm 110$ & $103.2 \pm 2.5$ & $0.96 \pm 0.05$ & $323 \pm 14$ & $208 \pm 23$ \\
\hline IS & $-50.5 \pm 1.5$ & $844 \pm 77$ & $93.3 \pm 1.5^{* *}$ & $0.90 \pm 0.02$ & $272 \pm 8^{*}$ & $140 \pm 24$ \\
\hline
\end{tabular}

All values are average \pm SEM.

${ }^{*} p<0.05$ compared with ES, ${ }^{* *} p<0.01$ compared with ES (Tukey's HSD).

HC ( $n=10$ rats, 18 neurons), ES ( $n=8$ rats, 15 neurons) and IS ( $n=7$ rats, 14 neurons).

electric tail-shocks were administered through copper electrodes augmented with electrode paste by a Precision Regulated Animal Shocker (Coulbourn Instruments) to rats restrained in $14 \times 11 \times 17 \mathrm{~cm}$ (length $\times$ width $\times$ height) acrylic boxes with a wheel $7 \mathrm{~cm}$ wide and 9.5 $\mathrm{cm}$ in diameter located on the wall opposite the tail. Each box was enclosed in a sound-attenuating chamber. Tail-shocks were presented on a variable-interval $60 \mathrm{~s}$ schedule. For rats that received ES, turning the wheel at the front of the chamber terminated each tail-shock after $1 / 4$ turn. If the response was performed within $5 \mathrm{~s}$ of shock onset, the response requirement doubled for the next trial and proceeded to a maximum of 4 wheel-turns. If the response was made after $20 \mathrm{~s}$, the requirement was reduced by half; if no response was made by $30 \mathrm{~s}$, the shock terminated and the requirement was reset to $1 / 4$ turn. To maintain escape behavior, the shock intensity was $1.0 \mathrm{~mA}$ for the first 33 trials, $1.3 \mathrm{~mA}$ for the following 33 trials, and $1.6 \mathrm{~mA}$ for the remaining 34 trials. Typically, experiments manipulating stressor controllability use a yoked design in which the rat without control (IS) is yoked to the rat with control (ES). Since only one rat per day could be used in electrophysiology studies, we chose to deliver IS on a schedule generated from archival ES escape latency data. On a trial-by-trial basis the mean escapable latency, the SD, the maximum latency, and minimum latency were computed from a random sample of 10 archival ES subjects. Each rat in the IS group received a unique series of 100 shocks. Shock durations were computed by taking a random interval from between the average minimum and the trial mean $\pm \mathrm{SD}$. If the maximum shock length was less than the mean \pm $\mathrm{SD}$, then the maximum shock length served as the range maximum. The algorithm produced a series of shocks akin to those generated by ES rats in the patch-clamp studies. Animals in the $\mathrm{HC}$ control group remained in their cages.

Social exploration tests. Each experimental subject was allocated a standard plastic tub cage with shaved wood bedding and a wire lid. Rats were placed in the test cage $60 \mathrm{~min}$ before the test. To begin the test, a 28 $( \pm 2)$-d-old juvenile was introduced to the cage for $3 \mathrm{~min}$, and exploratory behaviors (sniffing, pinning, and allogrooming) initiated by the adult were timed by an observer blind to treatment. Juveniles were used for multiple tests but were never used for the same adult rat.

Solutions and drugs. Standard artificial CSF (aCSF) and recording solutions were used (Sidiropoulou et al., 2009); aCSF composition was (in mM) $124 \mathrm{NaCl}, 2.5 \mathrm{KCl}, 26 \mathrm{NaHCO}_{3}, 2 \mathrm{MgCl}_{2}, 2 \mathrm{CaCl}_{2}$, and 10 glucose, $\mathrm{pH}=7.4,310 \mathrm{mOsm} / \mathrm{L}$; and the recording solution (in $\mathrm{mm}$ ), $115 \mathrm{~K}^{+}$-Gluconate, $10 \mathrm{HEPES}, 20 \mathrm{KCl}, 2 \mathrm{MgCl}_{2}, 3 \mathrm{Na}_{2} \mathrm{ATP}, 0.3$ $\mathrm{Na}_{2}$ GTP, $0.1 \%$ biocytin, $\mathrm{pH}=7.3,280$ mOsm. Biocytin, $0.3 \%$ (Sigma), was added to the recording solution to visualize the recorded cell type and location.

Prefrontal cortex slices. Rats were anesthetized with isoflurane, perfused with $\mathrm{aCSF}\left(4^{\circ} \mathrm{C}\right)$, brains were extracted, and $300 \mu \mathrm{m}$ coronal slices were taken from the prefrontal cortex using a vibratome (VT-1000P, Leica Microsystems). Slices were placed in oxygenated aCSF $\left(95 \% \mathrm{O}_{2}\right)$ at $35^{\circ} \mathrm{C}$
Table 3. Summary of input- output properties

\begin{tabular}{lll}
\hline Treatment & Rheobase $(\mathrm{pA})$ & Slope $(\# A \text { Ps } / \mathrm{pA})^{a}$ \\
\hline HC & $150 \pm 16$ & $0.147 \pm 0.015$ \\
ES & $178 \pm 28$ & $0.143 \pm 0.016$ \\
IS & $146 \pm 17$ & $0.125 \pm 0.014$ \\
\hline
\end{tabular}

All values are average \pm SEM.

${ }^{a}$ Number of APs per second per $\mathrm{pA}$.

HC ( $n=10$ rats, 18 neurons), ES ( $n=8$ rats, 15 neurons) and IS ( $n=7$ rats, 14 neurons).

for $30 \mathrm{~min}$ and then room temperature until slices were removed for electrophysiological recordings.

Electrophysiology. Whole-cell current-clamp recordings were obtained at $33 \pm 2^{\circ} \mathrm{C}$. Patch-clamp electrodes were pulled (Flaming/Brown P-97, Sutter Instruments) from $1.5 \mathrm{~mm}$ outer diameter borosilicate glass (Sutter Instruments) and filled with a K-gluconate-based intracellular solution. Electrode resistance was 3-4 M $\Omega$ in the bath and series resistance was $<30 \mathrm{M} \Omega$ during the recordings. Slices were visualized using a $40 \times$ water-immersion objective (Zeiss) mounted on an Infinity-tube FM-100 (Infinity). Current-clamp recordings were obtained with a BVC-700 amplifier (Dagan), using appropriate bridge balance and electrodecapacitance compensation. Data acquisition and analysis were performed using custom software written for Igor Pro (WaveMetrics Inc.). Separate between-group ANOVAs were conducted on each endpoint. Significant results were followed by Tukey's HSD post hoc tests to control experiment-wise type I error at $\alpha=0.05$.

Histology. After recording, the slice was removed from the recording chamber and placed in $4 \%$ paraformaldehyde. Neurons were visualized by incubation with $\mathrm{ABC}$ reagent (PK-6100, Vector Labs) and diaminobenzidine (Sigma-Aldrich) solution ( 1 tablet $/ 5 \mathrm{ml})$. Slices were floated onto glass slides and coverslipped (DPX mounting solution, SigmaAldrich). Only neurons with a pyramidal morphology and soma in PL layers $5 / 6$ were included for analysis.

Computer model. A "ball and stick" model was constructed using the program NEURON (www.neuron.yale.edu) and all the conductances were taken from the ModelDB database (Migliore et al., 2003). The model had the following dimensions: the soma was $80 \mu \mathrm{m}$ long $\times$ $10 \mu \mathrm{m}$ in diameter ( 3 compartments), and the dendrite was $400 \mu \mathrm{m}$ long $\times 2 \mu \mathrm{m}$ in diameter (10 compartments). The following conductances were used (by ModelDb accession numbers): $\mathrm{Na}$ (19696), $I_{\mathrm{H}}$ (135839), $K_{\mathrm{d}} \mathrm{r}$ (112546), $K_{\mathrm{A}}$ (108459), $\mathrm{Ca}_{\mathrm{T}}$ (119266) and $I_{\mathrm{CAN}}$ (12631). Only the soma had $\mathrm{Ca}_{\mathrm{T}}$ and $I_{\mathrm{CAN}}$. All fits were performed with the Runfitter function in the NEURON program. In brief, the function recursively adjusted the conductances automatically until the simulated trace converged on the experimental trace (see Fig. $2 \mathrm{~A}$ ) with a mean square root error of $<0.5 \%$. The model files are available online (http://www.neuro-cloud.net/nature-precedings/varela). 


\section{Results}

Because we used archival data to simulate yoking of ES and IS subjects, we first assessed whether the ES/IS procedure produced a behavioral outcome akin to that in prior work. IS decreased interaction $\left(t_{(7)}=2.41, p<0.05, n=8\right.$, two-tailed $t$ test $)$ with a juvenile $(72.5 \pm 5.5 \mathrm{~s}$, mean \pm SEM) $24 \mathrm{~h}$ after treatment compared with pre-interaction $(87 \pm 3.0 \mathrm{~s})$. In contrast, ES did not change the interaction time from before $(93.2 \pm 4.7 \mathrm{~s})$ to after ES treatment $\left(97.5 \pm 6.2 \mathrm{~s}, t_{(7)}=0.56\right.$, N.S., $n=8$, two-tailed $t$ test). Thus, the procedure resulted in a behavioral phenotype similar to that in prior reports (Christianson et al., 2010).

We proceeded to test the hypothesis that stressor controllability will induce plasticity of excitability in layer 5/6 PL pyramidal neurons. We focused on measurement of the basic intrinsic properties of the pyramidal neurons $2 \mathrm{~h}$ after ES, IS, or $\mathrm{HC}$ control, because changes in the intrinsic electrophysiological properties of $\mathrm{mPFC}$ neurons have been observed in this time frame after fear conditioning and extinction (Santini et al., 2008). We measured passive properties, current inputoutput curves (I-O), and single action potential (AP) properties. Results are summarized in Tables 1 to 3 .

\section{Passive properties}

Passive properties were measured by injecting $500 \mathrm{~ms}$ current pulses through the patch electrode from a holding membrane potential of $-67 \mathrm{mV}$. The amplitude of the current injections was usually between $-150 \mathrm{pA}$ and $+150 \mathrm{pA}$ with $25 \mathrm{pA}$ steps; the steps were randomized by trial. If in any trial an AP was elicited, that trace was eliminated from the analysis. We found no differences between the three groups in the Resting Potential, Input Resistance, Rectification or Sag ratio (Table 1; Spruston and Johnston, 1992). The membrane time constant was determined by applying a single-exponential curve to the decay of the -25 pA step pulse (Fig. $1 B$ ); the time constant of the fit was equal to the membrane time constant. A main effect of stress was found on the membrane time constant (Fig. $1 C, F_{(2,44)}=7.06, p<0.01$ ); the time constant of the ES group was significantly shorter compared with the $\mathrm{HC}$ and the IS groups $(p<0.05)$.

\section{Input-output properties}

Depolarizing $500 \mathrm{~ms}$ current pulses were injected through the patch electrode from $+100 \mathrm{pA}$ to $750 \mathrm{pA}$ in variable-current steps. All traces where APs were elicited were considered and the total number of APs per second was plotted against the current

A

C
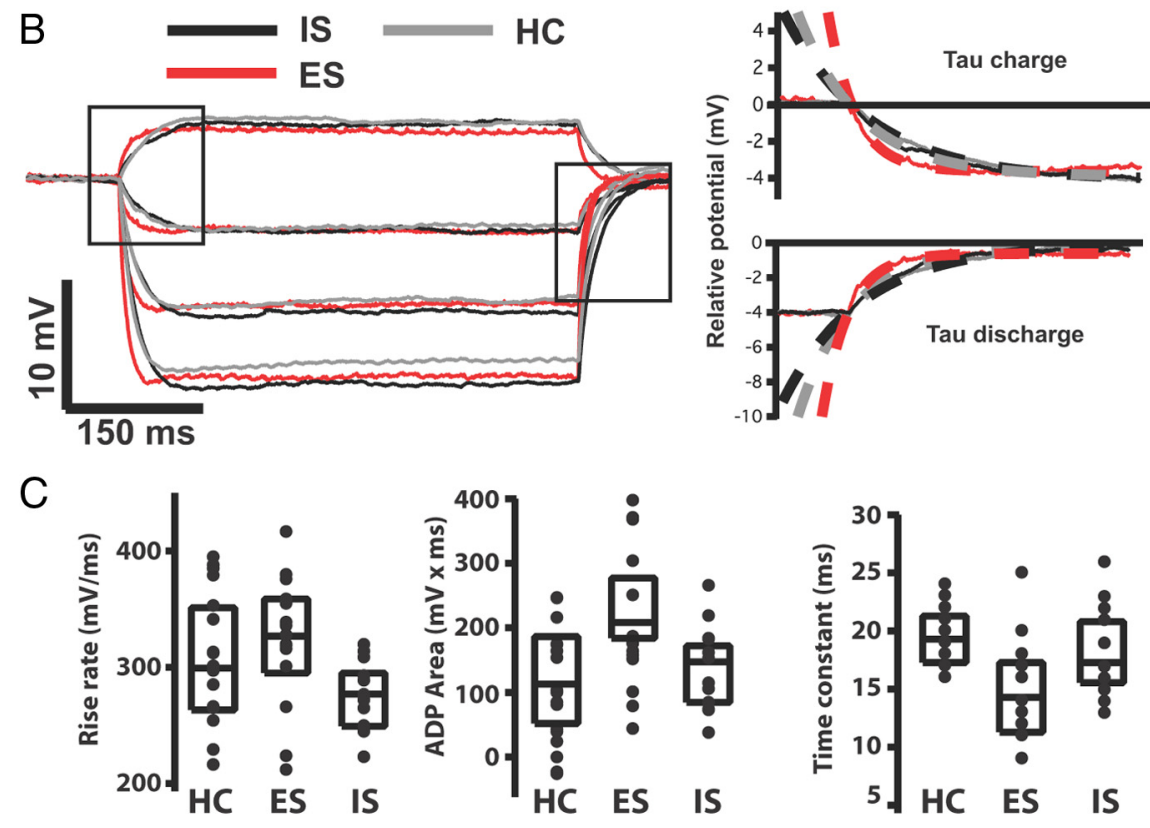

Figure 1. PL mPFC layer 5/6 pyramidal neurons from the ES group exhibit increased excitability compared with those from IS and HC groups. $A$, Left, Representative traces from ES (red) and IS (black) neurons. Top right, First derivative ( $d V / d t)$ of the AP is shown on the left; upper dashed line marks maximum rise rate and lower dashed line marks maximum fall rate. Bottom right, Expansion of the traces shown on the left; the shaded area shows the extent of the postspike afterdepolarization for the ES (red) and IS (black) neurons. $\boldsymbol{B}$, Left, Traces from neurons with similar input resistances belonging to HC (gray), ES (red), and IS (black). Top right, Expansion (left box) of the $-25 \mathrm{pA}$ traces from the left graph for all three groups. Single-exponential fittings (dotted lines) were calculated during the charging of the cell membrane. Bottom right, Expansion (right box) showing the same traces from the different groups at the beginning of the pulse. Single-exponential fittings (dotted lines) were calculated during the membrane discharge. C, Left, Action potential rise rate distribution (ES: $n=8$ rats, 15 neurons, HC: $n=10$ rats, 18 neurons, and IS: $n=7$ rats, 14 neurons). The line inside the box is the median and the boxes represent the first and third quartiles. Average spike amplitude from ES group rats is different from HC and IS groups. Middle, Afterdepolarization distribution (HC: $n=10$ rats, 18 neurons, ES: $n=$ 8 rats, 15 neurons and IS: $n=7$ rats, 14 neurons). ADP from ES group is larger from HC group. Right, Cell membrane time constant distribution (HC: $n=10$ rats, 18 neurons, ES: $n=8$ rats, 15 neurons, and IS: $n=7$ rats, 14 neurons). Time constant from ES group is different from both $\mathrm{HC}$ and IS groups.

injected to generate input-output curves. We found no differences among the groups (Table 2).

\section{Single spike properties}

AP properties directly reflect excitability. Neurons were held at $-67 \mathrm{mV}$ and $2.5 \mathrm{~ms}$ current pulses were injected to elicit a single AP. There were no differences in threshold or AP width between the groups (Table 3). However, we found a main effect of stressor treatment in the AP amplitude $\left(F_{(2,44)}=7.13, p<0.01\right)$. Post hoc comparisons revealed an increase in AP amplitude for the ES 

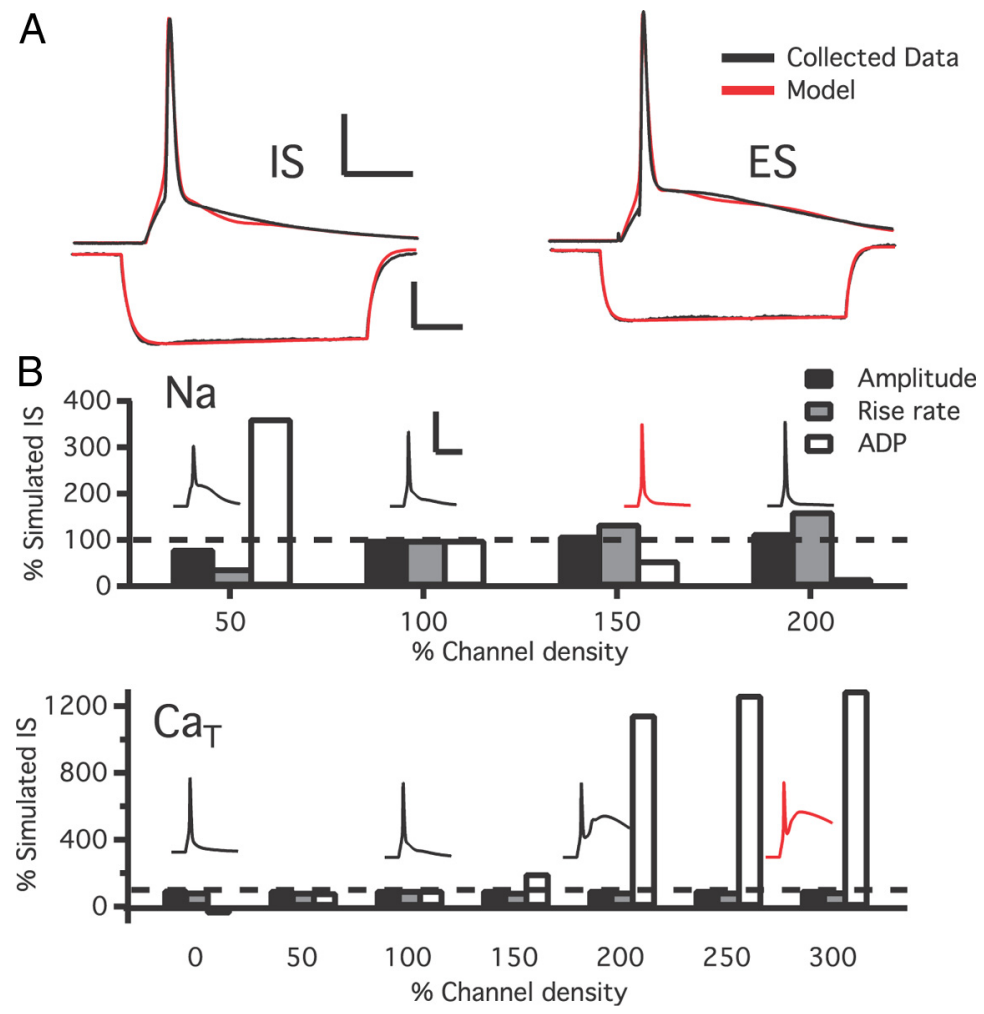

Figure 2. ES and IS computer models. $A$, Left, IS (black) action potential fit (red; calibration: $25 \mathrm{mV}, 5 \mathrm{~ms}$ ) and to a $-150 \mathrm{pA}$ current injection response (calibration: $10 \mathrm{mV}, 100 \mathrm{~ms}$ ). Right, ES (black) action potential fit (red) and to a $-150 \mathrm{pA}$ current injection response. $B$, Top, Simulated $g \mathrm{Na}^{+}$changes relative to IS (100\%). Insets, Simulated traces varying the $g \mathrm{Na}^{+}$: IS fit (100\%; calibration: $50 \mathrm{mV}, 20 \mathrm{~ms}$ ), ES fit (red, 163\%); $50 \%$ and $200 \%$ traces are shown for comparison. Bottom, Simulated $g \mathrm{Ca}_{\mathrm{T}}$ changes relative to IS (100\%). Insets, Simulated traces varying the $g\left(\mathrm{Ca}_{\mathrm{T}}\right.$ : IS fit (100\%), ES fit (red, $\left.285 \%\right), 0 \%$ and $200 \%$ traces are shown for comparison.

group compared with both IS and HC groups $(p<0.05)$. A main effect was also found on the slope of the rising phase of the AP $\left(F_{(2,44)}=3.67, p<0.05\right)$ with a faster AP rise rate in the ES group compared with the IS group $(p<0.05)$, but no difference from the HC group.

A characteristic of mPFC layer $5 / 6$ pyramidal neurons is the postspike ADP. The ADP is generated, in part, by the opening of voltage-dependent $g \mathrm{Ca}_{\mathrm{T}}$ during the AP (Yang et al., 1996). Since the peak of the ADP with respect to the AP varies from neuron to neuron, we measured a fixed area starting at spike termination and ending $50 \mathrm{~ms}$ later (Fig. $1 \mathrm{~A}$ ). We found a significant main effect of stress on the ADP (Fig. $2 C, F_{(2,44)}=4.03, p<0.05$ ). A significantly larger ADP area was found in the ES group compared with the HC group $(p<0.05)$, but IS did not differ from either ES or HC.

\section{Computer model}

The changes observed in the time constant, AP amplitude, AP rise rate, and ADP reflect changes in the underlying ion channel conductances and their interactions. To quantify the changes, we created computer models to fit the collected data. We inserted Hodgkin and Huxley-type conductances for the leak, $g \mathrm{Na}$, and delayed rectifier $\left(g K_{\mathrm{DR}}\right)$, and also A-type $\left(g K_{\mathrm{A}}\right), g \mathrm{Ca}_{\mathrm{T}}$, hyperpolarized-activated $\left(\mathrm{g} I_{\mathrm{H}}\right)$ and nonspecific voltage-dependent cation $\mathrm{g} I_{\mathrm{CAN}}$. These conductances are present in cortical neurons and have been modeled (Migliore et al., 2003).

There were no statistical differences between the HC and IS groups, so they were pooled in a control group $(p>0.05$ for all parameters, two-tailed $t$ test). The ES group differed significantly from the combined control group in AP amplitude $\left(t_{(46)}=3.17, p<0.001\right)$, AP rise rate $\left(t_{(46)}=2.00, p<0.05\right)$, and ADP $\left(t_{(46)}=2.44, p<0.01\right)$ and membrane time constant $\left(t_{(46)}=3.30, p<0.001\right.$, two-tailed $t$ test for all measures). We then proceeded to choose a "representative" IS neuron from the control data to fit against a representative ES neuron (Fig. 2 A). First we fitted the hyperpolarized steps in the IS trace and then decreased the leak conductance by $\sim 13 \%$ to fit the ES trace and account for the difference in membrane time constant. We then systematically varied the $g \mathrm{Na}^{+}, g K_{\mathrm{DR}}$, and $g K_{\mathrm{A}}$ which, in part, determines the shape of the AP. We varied the $g \mathrm{Ca}_{\mathrm{T}}$ and $g I_{\mathrm{can}}$ channels, which, in part, determine the ADP. While each conductance change altered the shape of the control trace, only increasing $g \mathrm{Na}^{+}$ and $g \mathrm{Ca}_{\mathrm{T}}$ produced a close fit to the AP rise rate, $\mathrm{AP}$ amplitude and $\mathrm{ADP}$ kinetics in the ES condition (Fig. 2B). Increasing $g \mathrm{Na}^{+}$by $163 \%$ and $g \mathrm{Ca}_{\mathrm{T}}$ by $285 \%$, relative to the control trace simulated the ES condition shown in Figure $2 \mathrm{~A}$.

In addition, we varied other conductances such $g I_{\mathrm{H}}$, which had no significant effect on AP amplitude, raise rate or ADP and $g I_{\mathrm{CAN}}$, which had no effect on AP amplitude or rise rate and only affected the ADP decay. Although altering gI $I_{\text {CAN }}$ broadened the ADP by slowing the decay, the kinetics were too slow and did not match those observed in the ES condition. Overall, the empirical data and simulations suggest that ES increases neuronal excitability. A larger ADP would increase the likelihood of multiple APs in response to brief excitatory inputs occurring within the ADP (Sidiropoulou et al., 2009). We used the simulated ES and IS models to test this hypothesis. We delivered a train of 10 synaptic inputs $20 \mathrm{~ms}$ after an evoked AP in both models, varying the frequency of the train from 10 to $100 \mathrm{~Hz}$, and the amplitude (at the soma) of the individual synaptic responses from 5 to 11 $\mathrm{mV}$ (lower amplitudes resulted in no elicited AP and larger amplitudes resulted in saturation of the model). The ES simulation resulted in more APs for all frequencies and amplitudes compared with the IS simulation (Fig. 3A). Due to the increases in $g \mathrm{Na}^{+}$in the ES model, it is expected that synaptic amplification, the increase in amplitude and duration of the postsynaptic response to synaptic inputs near AP threshold (Williams and Stuart, 1999), would be more predominant in the ES compared with the IS condition. We tested this hypothesis in the model by simulating a $5 \mathrm{mV}$ synaptic response at a holding potential of $-70 \mathrm{mV}$ and gradually increasing the holding potential (Fig. $3 B$ ) as we have previously described. Larger EPSP amplitude and area (i.e., greater synaptic charge) was observed in the ES compared with IS condition. Last, increased $g \mathrm{Na}^{+}$would facilitate synaptic summation in the ES group compared with the IS group. We tested this hypothesis and quantified the results across a wide range of amplitudes $(5-12 \mathrm{mV})$ and frequencies $(10-100 \mathrm{~Hz})$ for a train of 10 subthreshold synaptic inputs (Fig. 3C). The synaptic area in- 
creased preferentially in the ES condition as a function of the amplitude of the synaptic response and input frequency.

\section{Discussion}

The data indicate that controllable stressor exposure increases excitability of deep layer pyramidal cells of the PL, but uncontrollable stressor exposure led to no observable changes. The membrane time constant was shorter, the AP amplitude was larger, the AP rise rate was faster, and the postspike afterdepolarization area was larger in neurons from the ES group compared with IS or HC. Together these changes would render an ES neuron more responsive to subthreshold excitatory and inhibitory inputs, release more neurotransmitter and fire multiple APs more easily and possibly allow the neuron to burst. The computational model was able to simulate the observed changes in the ES group with a solution involving changes in only $g \mathrm{Na}^{+}$and $g \mathrm{Ca}_{\mathrm{T}}$. The model demonstrated how increases in these conductances would produce nonlinear amplification of subthreshold excitatory input near threshold and facilitate summation of high-frequency $(\sim 50 \mathrm{~Hz})$ inputs. The functional consequence would be to enhance synaptic gain and the induction of synaptic plasticity.

Only a few studies have used patchclamp techniques in the PL after stress exposure; none have manipulated stressor controllability. A prevailing view is that stress leads to loss of prefrontal cortex function (Arnsten, 2009), and this is supported by findings of enhanced GABAmediated IPSCs (Tan et al., 2004) and reduced EPSCs in PL (Li et al., 2011). The fact that we found no significant effects of IS on intrinsic properties suggests that the detrimental effects of stress on prefrontal cortex function may occur through a presynaptic mechanism.

Simply exciting the mPFC is sufficient to produce acute and long-lasting behavioral resilience. Increasing excitability of the mPFC by local infusion of the GABA antagonist picrotoxin to the PL/IL border during IS produced lasting immunization to later stress (Amat et al., 2006). Using a retrograde tracer Baratta et al. (2009) demonstrated that prior exposure to ES caused activation of PL to dorsal raphe nucleus (DRN) projection neurons upon exposure to uncontrollable stress 1 week later. Thus, we argued that plasticity in the PL-DRN neurons is critical to the behavioral immunization phenomenon (Maier and Watkins, 2010). Exposure to controllable stress may induce plasticity in multiple circuits of the mPFC. For example, ES blunts later fear expression but this effect requires IL (Baratta et al., 2008). Future studies will determine whether changes in $\mathrm{Na}^{+}$and $\mathrm{Ca}_{\mathrm{T}}$ channel function, might contribute to the long-term stress resilience conferred by ES.

\section{References}

Amat J, Baratta MV, Paul E, Bland ST, Watkins LR, Maier SF (2005) Medial prefrontal cortex determines how stressor controllability affects behavior and dorsal raphe nucleus. Nat Neurosci 8:365-371.

Amat J, Paul E, Zarza C, Watkins LR, Maier SF (2006) Previous experience with behavioral control over stress blocks the behavioral and dorsal raphe nucleus activating effects of later uncontrollable stress: role of the ventral medial prefrontal cortex. J Neurosci 26:13264-13272.

Arnsten AF (2009) Stress signalling pathways that impair prefrontal cortex structure and function. Nat Rev Neurosci 10:410-422.

Baratta MV, Lucero TR, Amat J, Watkins LR, Maier SF (2008) Role of the ventral medial prefrontal cortex in mediating behavioral control-induced reduction of later conditioned fear. Learn Mem 15:84-87.

Baratta MV, Zarza CM, Gomez DM, Campeau S, Watkins LR, Maier SF (2009) SF Selective activation of dorsal raphe nucleus-projecting neurons in the ventral medial prefrontal cortex by controllable stress. Eur J Neurosci 30:1111-1116.

Christianson JP, Ragole T, Amat J, Greenwood BN, Strong PV, Paul ED, Fleshner M, Watkins LR, Maier SF (2010) SF 5-hydroxytryptamine $2 \mathrm{C}$ receptors in the basolateral amygdala are involved in the expression of anxiety after uncontrollable traumatic stress. Biol Psychiatry 67:339-345.

Christianson JP, Drugan RC, Amat J, Rozeske RR, Aleksejev R, Watkins LR, Maier SF (2011) The long-lasting stress-protective effects of controlla- 
ble stress depend on plasticity in the prelimbic medial prefrontal cortex. Soc Neurosci Abstr 37:512.26.

Li N, Liu RJ, Dwyer JM, Banasr M, Lee B, Son H, Li XY, Aghajanian G, Duman RS (2011) Glutamate N-methyl-D-aspartate receptor antagonists rapidly reverse behavioral and synaptic deficits caused by chronic stress exposure. Biol Psychiatry 69:754-761.

Maier SF, Watkins LR (2005) Stressor controllability and learned helplessness: the roles of the dorsal raphe nucleus, serotonin, and corticotropinreleasing factor. Neurosci Biobehav Rev 29:829-841.

Maier SF, Watkins LR (2010) Role of the medial prefrontal cortex in coping and resilience. Brain Res 1355:52-60.

Migliore M, Morse TM, Davison AP, Marenco L, Shepherd GM, Hines ML (2003) ModelDB: making models publicly accessible to support computational neuroscience. Neuroinformatics 1:135-139.

Santini E, Quirk GJ, Porter JT (2008) Fear conditioning and extinction differentially modify the intrinsic excitability of infralimbic neurons. J Neurosci 28:4028-4036.

Sidiropoulou K, Lu FM, Fowler MA, Xiao R, Phillips C, Ozkan ED, Zhu MX, White FJ, Cooper DC (2009) Dopamine modulates an mGluR5-mediated depolarization underlying prefrontal persistent activity. Nat Neurosci 12:190-199.

Sotres-Bayon F, Quirk GJ (2010) Prefrontal control of fear: more than just extinction. Curr Opin Neurobiol 20:231-235.
Southwick SM, Vythilingam M, Charney DS (2005) The psychobiology of depression and resilience to stress: implications for prevention and treatment. Annu Rev Clin Psychol 1:255-291.

Spruston N, Johnston D (1992) Perforated patch-clamp analysis of the passive membrane properties of three classes of hippocampal neurons. J Neurophysiol 67:508-529.

Tan H, Zhong P, Yan Z (2004) Corticotropin-releasing factor and acute stress prolongs serotonergic regulation of GABA transmission in prefrontal cortical pyramidal neurons. J Neurosci 24:5000-5008.

Williams JL, Maier SF (1977) Transituational immunization and therapy of learned helplessness in the rat. J Exp Psychol Anim Behav Proc $3: 240-253$

Williams SR, Stuart GJ (1999) Mechanisms and consequences of action potential burst firing in rat neocortical pyramidal neurons. J Physiol 521:467-482.

Yang CR, Seamans JK, Gorelova N (1996) Electrophysiological and morphological properties of layers V-VI principal pyramidal cells in rat prefrontal cortex in vitro. J Neurosci 16:1904-1921.

Yehuda R, Flory JD, Southwick S, Charney DS (2006) Developing an agenda for translational studies of resilience and vulnerability following trauma exposure. Ann N Y Acad Sci 1071:379-396. 